Article

\title{
A Co-Created Methodological Approach to Address the Relational Dimension of Environmental Challenges: When Critical Legal Analysis Meets Illustrated Storytelling
}

\author{
Margherita Paola Poto ${ }^{1,2, *(D)}$ and Arianna Porrone ${ }^{3}$ \\ 1 Faculty of Law, UiT The Arctic University of Norway, 9011 Tromsø, Norway \\ 2 Department of Management, University of Turin, 10100 Turin, Italy \\ 3 Department of Political Science, Communication and International Relations, University of Macerata, \\ 62100 Macerata, Italy; a.porrone@unimc.it \\ * Correspondence: margherita.p.poto@uit.no
}

\section{check for}

updates

Citation: Poto, M.P.; Porrone, A. A Co-Created Methodological

Approach to Address the Relational

Dimension of Environmental

Challenges: When Critical Legal

Analysis Meets Illustrated

Storytelling. Sustainability 2021, 13,

13212. https://doi.org/10.3390/

su132313212

Academic Editors: António Raposo and Heesup Han

Received: 9 October 2021

Accepted: 25 November 2021

Published: 29 November 2021

Publisher's Note: MDPI stays neutral with regard to jurisdictional claims in published maps and institutional affiliations.

Copyright: (c) 2021 by the authors. Licensee MDPI, Basel, Switzerland. This article is an open access article distributed under the terms and conditions of the Creative Commons Attribution (CC BY) license (https:// creativecommons.org/licenses/by/ $4.0 /)$.
Abstract: Environmental education research needs to take into account the relational dimension of the ecological challenges of our time. It requires the development of methodological techniques that prioritize community concerns, and generally foster positive relational dynamics of the research and study group. This leads to the construction of a research and educational approach around the collective and cocreated interpretation of stories related to ecological bonds and knowledge, and the adoption of illustrations enabling participation, inclusion, and interaction among the parties. Through the lens of critical legal analysis and participatory research, we explore the beneficial effects of cocreating knowledge with the help of a specific learning toolkit (LT), built around storytelling and designed to stimulate respectful relationships between participants. The LT addresses a wide audience of indigenous and local communities, students, and researchers. Founded on participated storytelling, collective interpretation, and illustration, the toolkit includes (1) the project cover, (2) an illustrated handbook based on an indigenous story, and (3) the illustration and conceptualization of a silent book. Through the interpretation of stories on the ecological bonds between humans and nonhumans, we analyze how the process of looking for common solutions to environmental threats makes participants reflect on their relational connection to the theme and each other. We also observe how the discussion generates a sense of responsibility that comes with bringing a new idea into being. The result is that both education and research become part of the solution to the challenge itself in the shape of a harmonious relational and transformative experience. The solution lies in the recognition of the individual and collective capacity to change systems by changing relationships. Only through a collective effort towards a common sense of relational accountability and trust we can heal the wounds of our planet, and our individual and collective wounds.

Keywords: participatory; learning; critical; legal; theory; integral; ecology; relational

\section{Introduction}

"The idea of a system of infinite relationships between everything and everything else" (I. Calvino, Six Memos for the Next Millennium, 1988).

Legal, philosophical, and spiritual reflections on environmental ethics converge in the belief that the ecological crisis of our time reflects the dysfunction of the human and nonhuman relationship [1-9]. As Karen O'Brien puts it, 'Adaptation involves more than simply accommodating the impacts of climate change: it is also about confronting the societal context in which these changes are occurring' [5]. This study develops from the premise that a participatory approach in environmental legal studies contributes to the improvement of the societal context in academia and research. Such an improvement is crucial to address environmental challenges, considering the key role played by academia and research as fundamental incubators in the support and advancement of environmental 
solutions. Therefore, in the attempt to provide a scientific response to ecological relational dysfunctions, this study explores the applications of a novel methodological approach that combines critical legal thinking, participatory learning and action (PLA), and art-based (ARB) research. The interdisciplinary study of the ecological crisis applies a lens that brings together legal reflections, indigenous models of research and knowledge, and the narrative of ecofeminism, united in the aim of 'changing the system, not the climate' [10]. The system can be changed precisely by starting from the production, research, and teaching of knowledge, and thus from the world of research and education.

The novel combination of critical legal analysis with PLA [11-14] and ARB $[15,16]$ is relevant in light of Leavy's argument [16], according to which scientific and artistic methodologies bear intrinsic similarities since they both attempt to illuminate aspects of the human condition. The participatory and artistic inquiry is structured through workshops that involve communities of researchers and students, and foster their interaction.

The workshops are further embedded in the context of integral ecology (IE), intended as the integrated framework encompassing visible and nonvisible aspects of natural and social systems, which allows for decentering from the human dimension and focusing on the relational one $[17,18]$. In the world of research and scientific methodologies, the IE perspective translates exactly in the need for employing participatory processes aimed at cocreating solutions to current ecological challenges, which result in a relational problem or dysfunction. In this system, where 'the whole is greater than the part' [18]: (i) ecological solutions transcend disciplinary and sectoral boundaries; (ii) the subject-object dichotomy of research is critically revisited and overcome; and (iii) hierarchical power structures that are established in the scientific community are generally rethought, reread, and reinterpreted in the light of the values of care, relational accountability, respect, reciprocity, and responsibility.

An artistic and participatory process that looks into the environmental threats of our times through the perspective of IE may be more likely to find fertile terrain for an effective cocreation of the solution to the challenges insofar as IE unifies life as an intersubjective system $[17,18]$. IE looks into the ecological challenges to detect the symptoms of a relationship problem in the planetary wounds [19]. The transformational change that an artistic participatory approach of knowledge cocreation generates is expected to advance the body of solutions to the relational problems in the intersubjective system that is the IE.

\section{Materials and Methods}

\subsection{From Indigenous Methodology and Legal Design (LD) to the Learning Toolkit (LT)}

Our understanding of the role of cocreation of knowledge in the relational study of ecological issues is supported by theoretical and empirical approaches, both inspired by the (1) indigenous methodology [20] and (2) legal design. First, we developed our approach to relational research thanks to the training and the experience gained from the Indigenous Law Research Unit (ILRU), Victoria, British Columbia, Canada [21]. The ontological set of values that indigenous methodology brings to the table of a scientific approach to law and social studies is rooted in the idea that a continuously informed consciousness is generated within the community of research participants, where the relation of researcher-researched becomes irrelevant if not highly questionable, and where the ultimate goal is to explore how to change and improve the relational flow between participants and reality. In such a realization, there are numerous angles from which we draw insights, all valid and including ecofeminism, critical analysis, storytelling, and other multisensory experiences such as visual and illustrated narratives.

Second, we also developed our materials around the study of the communicative and evocative power of images in legal communication. The use of illustrations is a relatively new technique in legal research. Thanks to the research carried out by the Legal Design Lab at Standford University, coordinated by Margaret Hagan, in collaboration with the Faculty of Law and the Faculty of Design, illustrated language and legal research are also gradually establishing themselves as a discipline of study and an object of research [22-25]. 
Margaret Hagan, in particular, studied the stages of design thinking, observing how illustrations can complement the process of creating legal solutions centered on human needs. The researcher used the expression 'human-centred design approach' to define a methodological approach that aims to generate new forms of intervention and solutions to complex problems [25]. Using the technique of human-centredness, the needs of the parties are identified and graphically represented. This approach, according to Margaret Hagan, fits perfectly with PLA.

A final related field is legal participatory action research. Like a human-centered design approach, this form of action research also involves close work with the stakeholders in a given challenge area, and it encourages researchers to use interactions and creative work to produce new insights. Legal design borrows from the social science participatory action research approach. It involves researchers working alongside people whom they are studying or in the context that they want to understand [25].

Another cluster of excellence in the study of legal design, which integrates aspects of visual law and illustrated legal research on environmental issues, is being consolidated in Brazil, at the Universidade Federal do Estado do Rio de Janeiro, thanks to the research team coordinated by Giulia Parola, which sees the collaboration of a law firm, young researchers belonging to the indigenous Chiquitano people from Mato Grosso (in Brazil), and a group of legal design consultants [26-28].

Against this background, our methodology consists of a three-step process conveying into our LT that includes the following materials: (1) The ideation of the concept idea or project cover (2019); (2) development and testing of a handbook (2020); (3) illustration and conceptualization of a silent book (2021).

The concept idea of the LT was first launched with project cover An Illustrated Storybook on Indigenous Stories (Step 1, Figure 1) representing the interaction between two shape-shifter feminine spirits that voice (indigenous) stories. Both stories and storytellers mirror the fluid and immanent governing water and earth in such a way that can be understood by students, indigenous and nonindigenous researchers, and community members at large. The two spirits of water and earth intend to accompany the overall project as if it was an illustrated story of stories in itself, collecting narratives, ideas, and observations on the symbiotic relationship that governs communities and nature. The cover representing the idea was presented in 2019 during international workshop Kjønnsforskning NÅ!, endorsed by the Gender Research Group, at the UiT The Arctic University of Norway [29]. The idea to build bridges between different legal cultures and orders with the help of illustrations led to a successful and well-received first project outcome, and the cover was published as a final scientific product. Hence, the inspiration to continue developing the idea to open creative venues for legal reflections.

Step 2 (Figure 2) of our LT was largely inspired by this work, with the creation and publication of handbook A Story About Knowledge, inspired by an Arctic story (based on the learning materials of the University of the Arctic, training module 4, edited by Gord Bruyere and Einar Bergland), and specifically rooted around an illustrated episode of the story [30].

The story was chosen for the focus on the search for the best place where to find and guard knowledge. The search is triggered by the Creator's request addressed to a trickster spirit, to find that place, and it is delegated from the trickster spirit to the animals of Earth (symbolically represented by a bear, an eagle, a salmon, and a mole). The search becomes an interactive, situated, and yet delocalized thought-provoking process. One of the protagonists of the story is the mole, gifted without apparent eyesight and with great vision. Knowledge is found and guarded in the heart of Earth, and it is the mole that, at a first sight, seems to solve the enigma. At a deeper level, though, the audience realizes that the solution is the result of a collective sum of apparently vain individual efforts of the other animals. The illustration, the narration of the story based on the illustration, and a series of lessons are the three core elements of the handbook. The lessons are developed 
around a character of the story, and are intended to stimulate reflections and debate around the roles of the characters in the unfolding of the story.

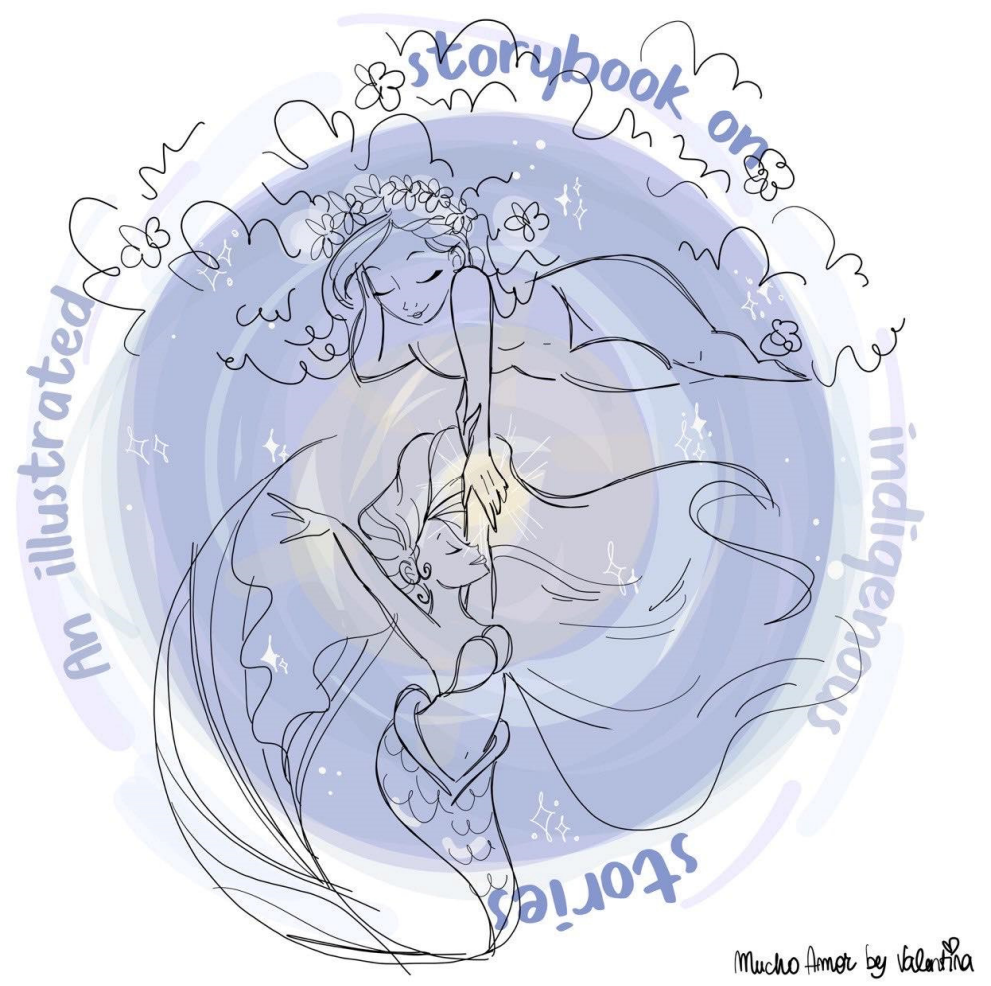

Figure 1. Concept idea. Illustrated storybook of indigenous stories as a learning tool for scholars and communities; illustration by Valentina Russo, Mucho Amor, 2019, published in https:/ / doi.org/10.7 $557 / 5.5040$.

\section{ASTORY ABOUT}

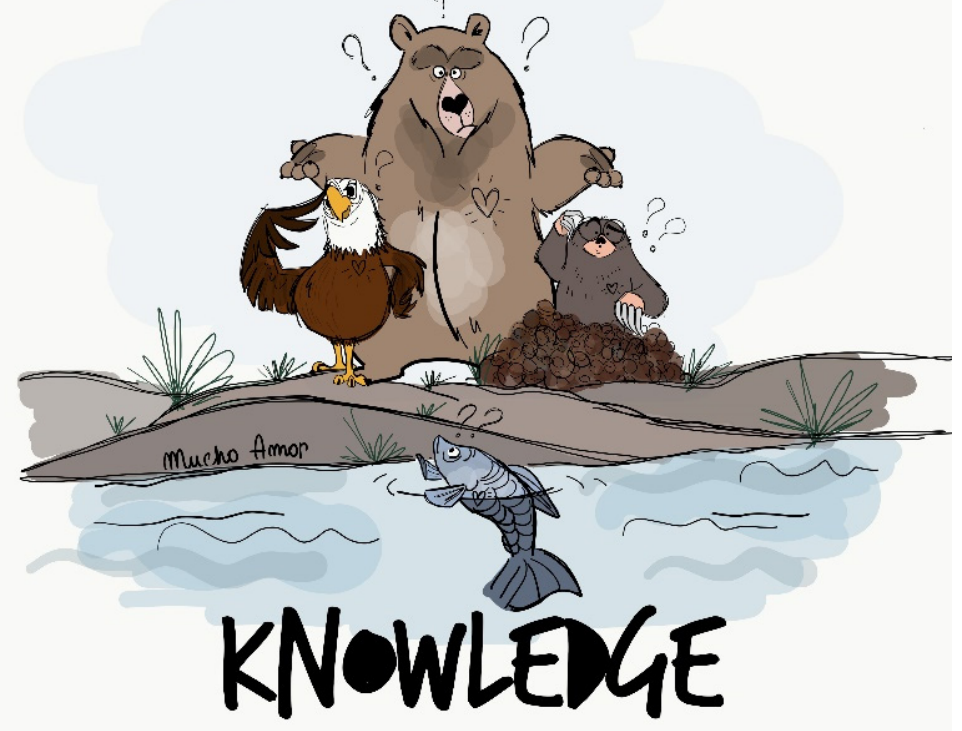

Figure 2. Handbook, colored version of the official book cover. A Story About Knowledge, illustrated by Valentina Russo, Mucho Amor, 2020. 
Step 3 (Figure 3), or the silent book [31], continues along the line of the conceptual idea (working on the relational aspect of ecology), this time situated in geographical and colored settings (the mountainside, airspace, the waterside, the underground). Five art prototypes display the five crucial moments of the animals' search for knowledge, and consequent full immersion in and interaction with their own environment. The key episodes were developed in the form of an illustrated book for kids of all ages, and ultimately as a silent book. The book aims to become eligible for the program of Silent Books: Final Destination Lampedusa, The IBBY Network [32], a book network that donates wordless books to a newly created library in Lampedusa. Our LT addresses a composite audience of university students, researchers, and the community at large, in person and face to face, and with digital research or facilitation.

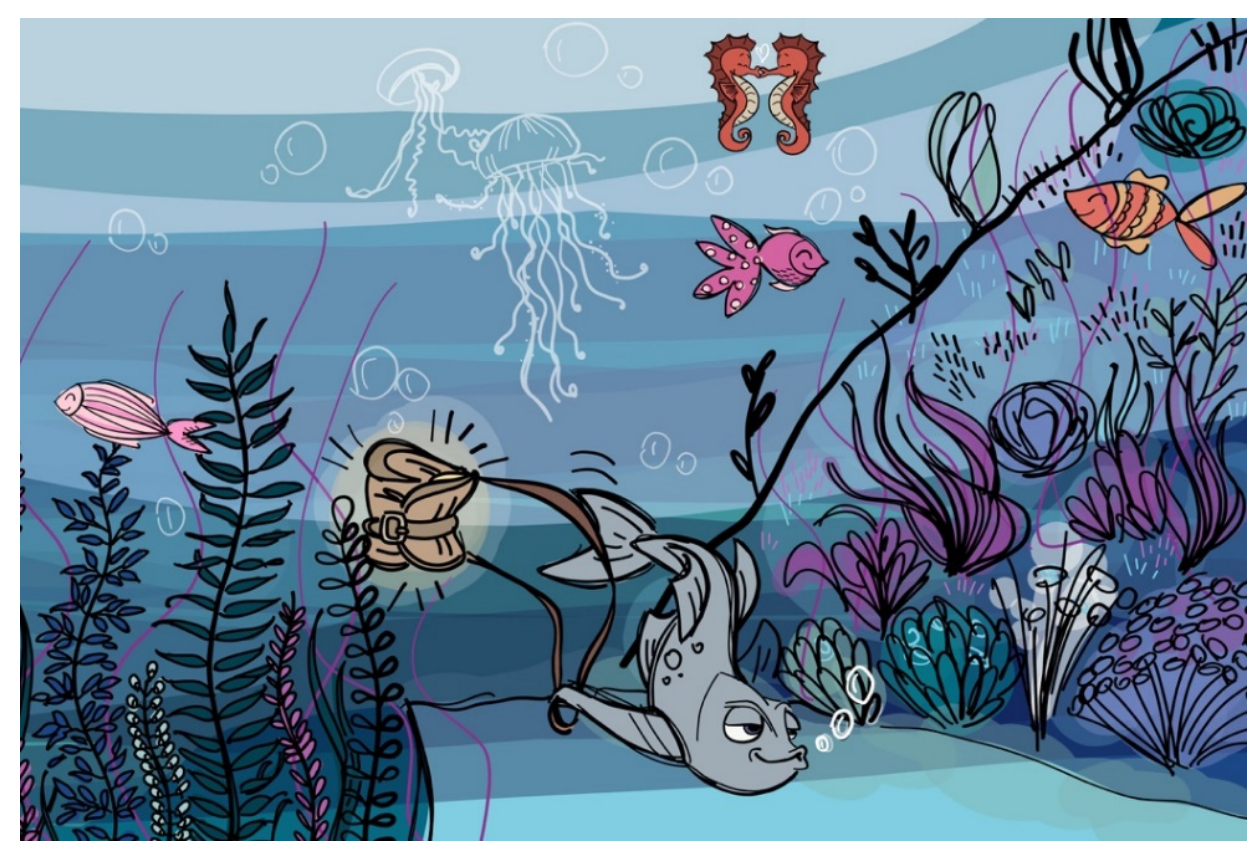

Figure 3. Image 4, excerpt, Russo, V. (illustrator). A Story About Knowledge. Illustrated version. ed. by A. Porrone and M. P. Poto, Aracne: Roma, forthcoming 2021.

\subsection{Testing the Foundations with Communities of Students and Researchers \\ Enhancing Environmental Reflections through a Consolidated Classroom Practice}

In mid-2020, we brought into play the LT through a set of seminars and a series of academic lectures that we held for young researchers and students in the fields of global studies, law, economics, and interdisciplinarity.

In particular, we integrated our Step 2 into university curricula: in an elective undergraduate course on administrative law and the agenda 2030, and on public law for economics (University of Turin, Italy, Department of Management; academic years: 20192022); in a module of the master's program on food security and safety (University of Turin, Italy, academic year: 2020). Moreover, we used the teaching material to lead a seminar on the theme of situated knowledges as part of the core activities complementing Year I and II students' doctoral training in Global Studies. Justice, Rights, Politics (University of Macerata, Italy, Department of Political Science, Communication and International Relations, Academic year: 2019-2020). Eventually, the teaching methodology was adopted in an interdisciplinary master's program on global health with a specific focus on Arctic governance (McMaster University, Hamilton, Ontario, Canada 2021).

Our approach to Step 2 of the LT steers the process of learning and environmental problem solving through a consolidated practice. Seminars and classes were designed to deepen the individual and collective awareness of the root causes of ecological wounds, and the role that participatory research and education can play in the wound-healing 
process. Before the seminar or class starts, we send an invitation to the participants to come prepared on a general reflection about their understanding of why their environment is degraded, and the role that they and other members of their communities and society at large play in this process. Where possible, we send the text of the story to the participants before the session with instructions for a preliminary reading.

Engagement with Step 2 of the LT follows a protocol that contains care and gratitude at its core. We thank the audience, the territory that embraces us (especially in cases of occupied lands), and the virtual space that hosts our meeting. At times, we initiate the conversation by reading the text of the story out loud, respecting breaks and silences in the text to slowly accompany readers into the story. Every time, we experience the power of reading out loud, the fully engaging exercise where all our energy as readers-narrators is put into the task without any distraction. It is a multisensory activity (engaging voice, hear, sight) that builds a strong connection between the mind and voice of the readers and the listeners. It seems comparable to the work of a solo player who interacts with an orchestra. The spoken word helps to strengthen our minds and take ownership of our ideas, filling in the room with sound and meaning, building bridges and connections between participants.

When our time is limited, after giving attendees time to read and reflect, we summarize the story's main points, focusing on the physical and psychological features of the animals and the symbolic integration in their environment.

After the story reading or telling, we listen to the audience's impressions and report back preliminary impressions (first reactions to an unconventional academic text, potential common themes, summaries of previous experiences with the same story or with illustrated storytelling) before initiating a deeper conversation around the subject matter. When we use the learning toolkit in teaching environments, we tend to ask our audience to work as a team to provide feedback, identify common key ideas that require refining, changing, or additions, and emphasize themes or ideas that resonate with them. Each animal's action or decision making is associated with a specific lesson, composed of an objective, keywords, questions, and an interactive activity.

Before, during, and after the sessions, participants are encouraged to engage with the handbook by providing written answers and their creativity. Creative answers by designing and coloring journaling prompts are highly encouraged and recommended. Multisensory experiences are part of the learning process and a proactive way to respond to the sequence of questions specifically designed for the project. Engaging with the story lesson through journaling exercises and prompts is part of a collective therapeutic process to bring about awareness on the need to heal the planet by healing our relationships and improving our overall health conditions by creatively engaging with inner and outer conflicts. The work outside the seminar room contributes to spur new conversations, allowing for us to discuss key issues in greater depth, elevating the richness and complexity of mutual understanding. Through these continued conversations, the key underlying principles forming a common conceptual framework of integral ecology were identified, for instance, in how the relationship with the environment and the peoples emerges from narratives, stories, and dreams, and what it entails in terms of rules and obligations for the communities.

Our sessions aim to self-empower and motivate participants to take action, develop relational strength through empathy, compassion, and care for each other and for the environment that surrounds them.

A typical structure for the conduction of activity through Step 2 of our LT is provided in Table 1. 
Table 1. Example of participatory techniques of self- and collective reflection through storytelling applied to education and research.

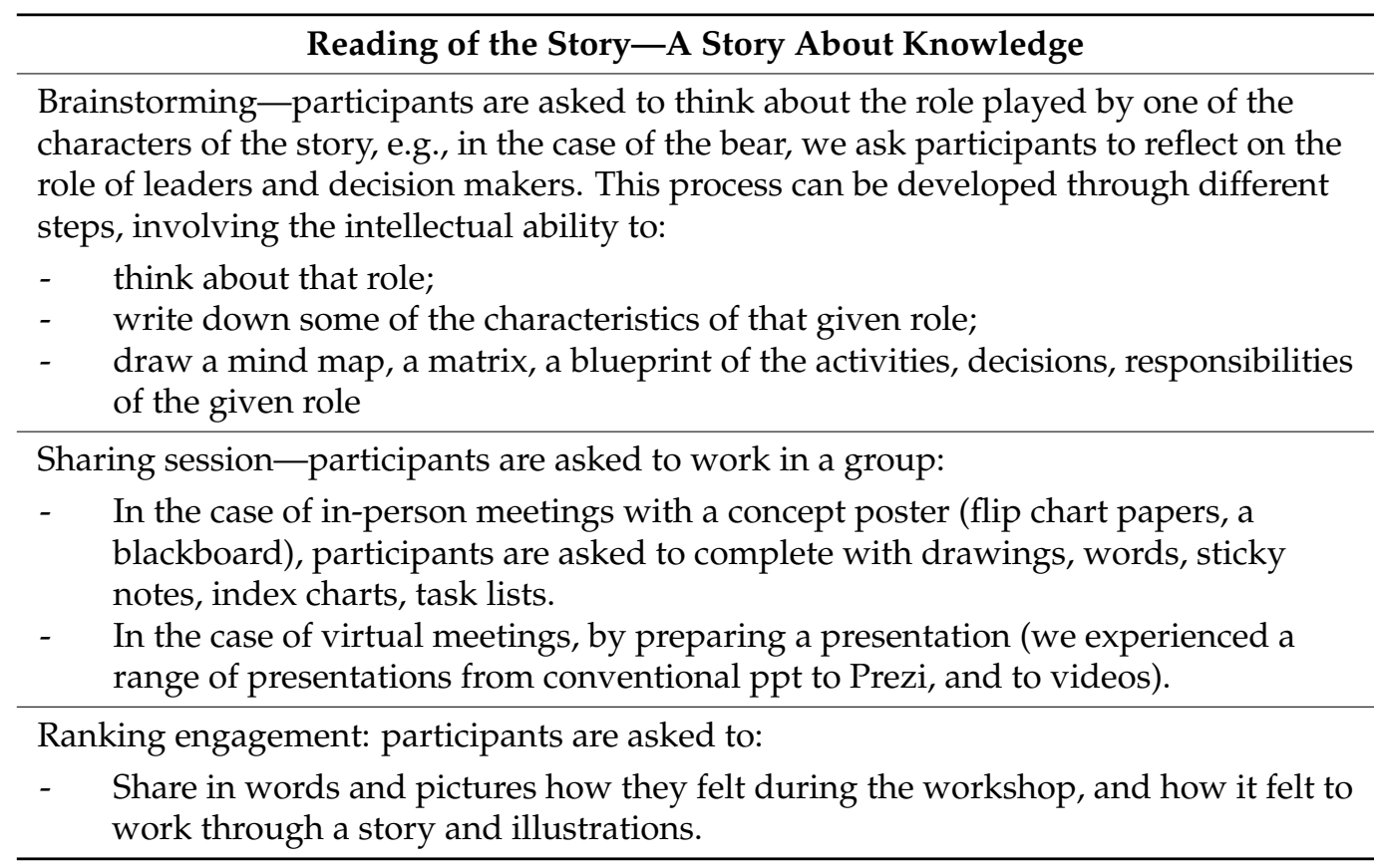

\section{Results and Discussion}

The research results of the cocreated approach include the organization of a workshop on Donna Haraway [33], with a focus on the need to rethink and reframe current ecological challenges through new stories with research group Social Dynamics in Marine and Coastal Areas (Kiel University, Germany, Department of Geography, Academic year: 2020-2021).

In particular, the workshop was held on a digital platform (Zoom) and accompanied by an interactive ppt (Canva) with research group Social Dynamics in Marine and Coastal Areas (Kiel University, Germany, Department of Geography), and benefited from a relaxed, friendly, and open atmosphere. Engagement with the story led the participants to unexpected scenarios. Reflecting with the help of an illustrated story is an unconventional method, especially in Western-based research contexts. The session facilitator played a key role by creating the rules of the game and the atmosphere to engage all participants in the common working space. The session opened with the story reading and the assignment of an active role to the participants. Participants were asked to reflect on the main research question with the help of the story, compare the story with other resources, share their opinions, and synthesize the results in a common conceptual framework. Results were then collectively reassessed, and rereading the story ends the workshop. In this case, it was the illustration of the mole and her underground world, filled with important questions (Porrone, Poto, 2021, such as 'How is wisdom related to the senses?', 'How is it related to individual and collective efforts?', and 'What does the earth teach to the researchers?') that guided the meditation.

Take-away reflections included questions on epistemology and methodology (e.g., on the actors involved in knowledge production, on the way knowledge is achieved, and on the purpose of such an achievement). Such issues and many others were discussed in a final group session, collectively and in a nonjudgmental space. All participants contribute to the cocreation of a healthy and respectful environment. A participant referred to this as a form of 'collective intelligence', open to unpredictable possibilities, a process that should also translate into the vocabulary of law and global studies. A research environment based on a healthy relationship between researchers has beneficial effects on the quality of the research content and ultimately on a healthy planet. 
The experience of delving into collaborative educational and research activities, and thus engaging in a reciprocal effort of cocreating and looking for solutions, shifts the conversation towards purpose, intention, and the consciousness of a common interconnected world. Discussing concerns for the natural environment, increased climate change threats, economic and social disparity, or inadequacy of the international legal tools to overcome the fragmentation of the actors and solutions, led us to reflective questions (e.g., "What is the ontological structure of nature that law should mimic?" and "How can we make the international community shift towards a novel conceptual structure?") or evaluative statements about action (e.g., "It will be the next generations who will suffer the most, which is why we have to build a sustainable model for future generations"). In a sense, these reflections develop a sense of relational accountability, as knowledge exchange and collective search for solutions are understood to be part of a ceremony [34], which raises the level of consciousness of our reciprocal duties to respect, honor, and care for each other and our environment.

Overall, the positive impact that the research has on the principal investigators is part of the success of the project. Following a protocol of respect and care for the place that is hosting gatherings teaches the coordinators the value of intellectual humility by the act of establishing a connection between people and the physical space that hosts them [35].

Moreover, erasing the divide of researchers and researched gives a new dimension to equality, where barriers between teacher and learner vanish, and the relational flow does not encounter hierarchical obstacles. Dealing with problems and solutions with the help of nonverbal languages, such as illustrations, silences, and sounds, provides a richer experience of the diverse approaches and relational attitudes towards a problem.

\section{Conclusions}

This paper analyzed the conceptually and methodologically rigorous approach to developing effective cocreated participatory and inclusive methods and techniques to deal with the challenges presented to the world of research and education by the ecological crisis. The cocreation of participatory and artistic approaches to research and teaching is configured as a methodological response to ecological challenges, through a perspective that takes into account the relational aspect that emerges from the ecological dysfunctionality. The theoretical approach to IE needs to be complemented with participatory empirical research that places the relationship between subject and object of research at the center of the investigation, suggesting a modus operandi that reconciles and ultimately overcomes the divide between researchers and object of research.

The new conceptual and methodological framework described here is extremely demanding for the communities of participants, researchers, and learners: it requires a considerable time commitment and engages participants' involvement in defining the relational dynamics between them, around the research question they are asked to answer. In these ways, our approach creates opportunities for transformative research and education to be propagated around inclusive and collective research and education spaces.

To gain further empirical evidence to support our approach, we are extending our participatory approach to focus groups from nature-connected community members, such as the indigenous river communities of Brazil and Northern Norway [36-38]. Along this path, future research could explore how this community-based approach could support environmental justice research, where researchers and learners could become actors of change and paladins of environmental justice $[39,40]$.

The whole process of cocreated methodological approaches to compelling legal questions on the environmental challenges contributes to an active and continuous process of knowledge shaping. Moreover, through the collective reflections of the participants, the approach contributes to the building of a new collective narrative and visualization of ecology, as a space where legal and global reflections are accompanied by the development of strong relational bonds among the parties involved in the research and education pat. The collective sharing of concerns for the natural environment, increased climate change 
threats, and the inadequacy of international legal tools to overcome the fragmentation of the actors and solutions develop a sense of relational accountability, as knowledge exchange and collective search for solutions are understood to be part of a ceremony $[34,41]$ that raises the level of consciousness of our duties to respect, honor, and care for each other and our environment.

By raising the environmental consciousness through collective research, it is possible to heal relational wounds and in this sense offer a solution to the environmental challenges, which are also and above all relational challenges, of our time. When brought into practice, the idea of a system of infinite relationships between everything and everything else becomes the collective solution to the ecological challenges of our times.

Author Contributions: Conceptualization, M.P.P. and A.P.; methodology, M.P.P. and A.P.; draft preparation, M.P.P. and A.P.; writing—review and editing, M.P.P. and A.P. All authors have read and agreed to the published version of the manuscript.

Funding: M.P.P.'s research was funded by UiT The Arctic University of Norway grant number ID-2061344 and by the funding HKDIR-Utforsk 2021-2024 (ECO_CARE).

Institutional Review Board Statement: Not applicable.

Informed Consent Statement: Not applicable.

Acknowledgments: The authors would like to thank Val Napoleon and Rebecca Johnson, ILRU, Canada, for the continuous inspiration, and Valentina Russo for illustrating our project ideas.

Conflicts of Interest: The authors declare no conflict of interest.

\section{References}

1. Francesco, P. Lettera Enciclica Laudato sì. Sulla cura della casa commune; Librería Editora Vaticana: Rome, Italy, 2015.

2. Petrini, C. Terrafutura: Dialoghi con Papa Francesco sull'ecologia integrale; Giunti: Florence, Italy, 2020.

3. Capra, F. 'Laudato Sì the Ecological Ethics and Systemic Thought of Pope Francis'. Available online: https://www.fritjofcapra. net/laudato-si-the-ecological-ethics-and-systemic-thought-of-pope-francis / (accessed on 26 November 2021).

4. Beato, F. I quadri teorici della sociologia dell'ambiente tra costruzionismo sociale e oggettivismo strutturale. Quad. Sociol. 1998, 16, 41-60. [CrossRef]

5. O'Brien, K. Climate Change and social transformations: Is it time for a quantum leap? Wiley Period. 2016, 7, 618. [CrossRef]

6. Poto, M.P. Salvare la nostra casa comune è l'Affaire du Siècle: Dall'infiammata protesta del popolo francese all'ingiunzione al Governo di ridurre le emissioni di gas serra. Tribunale Amministrativo di Parigi, IV Sez. I Camer. Resp. Civ. Prev. 2021, 3, 1-24.

7. Bai, X.; van der Leeuw, S.; O’Brien, K.; Berkhout, F.; Biermann, F.; Brondizio, E.S.; Cudennec, C.; Dearing, J.; Duraippah, A.; Glaser, M.; et al. Plausible and desirable futures in the Anthropocene: A new research agenda. Glob. Environ. Chang. 2016, 39, 351-362. [CrossRef]

8. O'Brien, K. Global environmental change III: Closing the gap between knowledge and action. Prog. Hum. Geogr. 2013, 37, 587-596. [CrossRef]

9. Sygna, L.; O’Brien, K.; Wolf, J. (Eds.) A Changing Environment for Human Security: Transformative Approaches to Research, Policy and Action; Routledge: London, UK, 2013.

10. Bianchi, B. Ecofeminism: The Ideas, the Debates, the Prospects. DEP 2012, 20, 1-26. (In Italian)

11. Morales, M.P.E. Participatory Action Research (PAR) cum Action Research (AR) in Teacher Professional Development: A Literature Review. Int. J. Res. Educ. Sci. 2015, 2, 156. [CrossRef]

12. Pretty, J.N.; Guijt, I.; Scoones, I.; Thompson, J. A Trainer's Guide for Participatory Learning and Action; IIED: London, UK, 1995.

13. Bozalek, V. Acknowledging Privilege through encounters with difference: Participatory Learning and Action technques for decolonizing methodologies in Southern contexts. Int. J. Soc. Res. Methodol. 2011, 14, 469-484. [CrossRef]

14. Keahey, J. Sustainable Development and Participatory Action Research: A Systematic Review. Syst. Pract. Action Res. 2021, 34, 291-306. [CrossRef]

15. Curtis, D.J.; Reid, N.; Reeve, I. Towards ecological sustainability: Observations on the role of the arts. SAPI EN. S. Surv. Perspect. Integr. Environ. Soc. 2014, 7. Available online: https://journals.openedition.org/sapiens/1655 (accessed on 26 November 2021).

16. Fernández-Giménez, M.E.; Jennings, L.B.; Wilmer, H. Poetic Inquiry as a Research and Engagement Method in Natural Resource Science. Soc. Nat. Resour. 2019, 32, 1080-1091. [CrossRef]

17. Capra, F. The Ecological Ethics and Systemic Thought of Pope Francis. Trumpeter 2018, 34, 2-13. [CrossRef]

18. Pope Francis. Encyclical Letter Laudato Si' ("Praise Be to You”). Available online: http://www.vatican.va/content/francesco/ en/encyclicals/documents/papa-francesco_20150524_enciclica-laudato-si.html (accessed on 18 November 2021). 
19. O'Brien, K.; Eriksen, S.; Inderberg, T.H.; Sygna, L. Climate change and development: Adaptation through transformation. In Climate Change Adaptation and Development; Routledge: London, UK, 2014; pp. 289-305.

20. Tuhiwai Smith, L. Decolonizing Methodologies: Research and Indigenous Peoples; Zed Books Limited: London, UK, 1999.

21. Indigenous Law Research Unit, University of Victoria. Available online: https://www.uvic.ca/law/about/indigenous/ indigenouslawresearchunit/index.php (accessed on 18 November 2021).

22. Margaret Hagan Website. Available online: https:/ /law.stanford.edu/directory/margaret-hagan/ (accessed on 1 May 2021).

23. Hagan, M. Legal Design as a Thing: A Theory of Change and a Set of Methods to Craft a Human-Centered Legal System. Des. Issues 2020, 36, 3-15. [CrossRef]

24. Hagan, M. Participatory Design for Innovation in Access to Justice. Daedalus 2019, 148, 120-127. [CrossRef]

25. Hagan, M. A human-centered design approach to access to justice: Generating new prototypes and hypotheses for interventions to make courts user-friendly. Ind. JL Soc. Equal. 2018, 6, 199.

26. Legal Hack. Available online: https:// fcmlaw.com.br/iniciativas/legal-hack/ (accessed on 18 November 2021).

27. Parola, G.; Poto, M.P. (Eds.) The Escazú Agreement in Comics with and for the Chiquitano People. A Co-Created Project of Legal Design and Visual Law; Giappichelli: Torino, Italy, 2021.

28. Parola, G.; Poto, M.P.P. Acordo o Escazú em Quadrinhos para o Povo Chiquitano; Giappichelli: Torino, Italy, 2021.

29. Septentrio Conference Series. Available online: https://septentrio.uit.no/index.php/SCS/article/view/5040 (accessed on 21 March 2021).

30. Porrone, A.; Poto, M.P.; Russo, V. A Story about Knowledg; Aracne: Rome, Italy, 2021. Available online: https://iris.unito. it/retrieve/handle/2318/1788183/759200/Mastro\%20Indice\%2014\%20x\%2021\%20ASAK_180432021final.pdf (accessed on 18 November 2021).

31. Porrone, A.; Poto, M.P.; Russo, V. A Story about Knowledge. The Illustrated Version; Aracne: Rome, Italy, 2021, forthcoming.

32. International Board on Books for Young People. Available online: https://www.ibby.org/awards-activities/activities/silentbooks (accessed on 1 March 2021).

33. Haraway, D.J. Staying with the Trouble. Making kin in the Chtulucene; Duke University Press: Durham, NC, USA, 2016.

34. Wilson, S. Research is Ceremony: Indigenous Research Methods; Fernwood Publishing: Black Point, NS, Canada, 2008.

35. Dickens, L.R. Using Gratitude to Promote Positive Change: A Series of Meta-Analyses Investigating the Effectiveness of Gratitude Interventions. Basic Appl. Soc. Psychol. 2017, 39, 193-208. [CrossRef]

36. An Exchange Program on Empathy, Compassion, and Care in Water Governance, from the Perspective of Integral Ecology(ECO_CARE). Available online: https://en.uit.no/project/ecocare (accessed on 17 November 2021).

37. Ribeiro, F.M.; da Costa, L.; Parola, G.; Poto, M.P. (Eds.) Inclusão, Coexistência e Resiliência: Lições a Partir do Direito e da Metodologia Indígenas; Multifoco: Rio de Janeiro, Brazil, 2021; pp. 1-331.

38. Parola, G.; Poto, M.P. (Eds.) Inclusion, Coexistence and Resilience: Key Lessons Learned from Indigenous Law and Methodology; Multifoco: Rio de Janeiro, Brazil, 2019.

39. Poto, M.P.; Porrone, A. The Steady Ascent of Environmental and Climate Justice: Constituent Elements and Future Scenarios. Resp. Civ. Prev. 2021, 4, 1-11. Available online: https://iris.unito.it/handle/2318/1813339\#. YaB3i9BByUk (accessed on 26 November 2021).

40. Poto, M.P. Salvare la Nostra Casa Comune e' l'Affaire du Siècle. Resp. Civ. Prev. 2021, 3, 1046-1059. Available online: https:/ /iris.unito.it/handle/2318/1790303\# (accessed on 26 November 2021).

41. Magnat, V. Can research become ceremony? Performance ethnography and Indigenous epistemologies. Can. Theatre Rev. 2012, $151,30-36$. 